\title{
Evaluation of Field Application of Soil Conditioner and Planting Chrysanthemum zawadskii on the Roadside Soils Damaged by Deicing Agents
}

\author{
Ji Yang ${ }^{1}$, Jae-Man Lee ${ }^{2}$, Yong-Han Yoon ${ }^{3}$, and Jin-Hee Ju ${ }^{3 *}$ \\ ${ }^{1}$ Doctor's student, Department of Green Technology Convergence, Graduate School, College of Science and Technology, Konkuk University, \\ 268 Chungwon-daero, Chungju-si, 27478, Korea \\ ${ }^{2}$ Master's student, Department of Green Technology Convergence, Graduate School, College of Science and Technology, Konkuk University, \\ 268 Chungwon-daero, Chungju-si, 27478, Korea \\ ${ }^{3}$ Professor, Department of Green Technology Convergence, College of Science and Technology, Konkuk University, 268 Chungwon-daero, \\ Chungju-si, 27478, Korea
}

\section{ABSTRACT}

Background and objects: Soil contamination caused by $\mathrm{CaCl}_{2}$ that is used to deice slippery roads in winter is now recognized as one of the major causes of damage of roadside plants. The aim of this study is to identify the salt mitigation effects of planting Chrysanthemum zawadskii and using a soil conditioner.

Methods: The study was conducted at the site where Pinus densifloraf. multicaulis was planted on the roadside between Konkuk University Sageori and Danwol Samgeori located in Chungju-si. We classified the soils collected from the field experimental site according to the degree of the damage caused by deicing agents and divided the site into six blocks of three $80 \times 80 \mathrm{~cm}$ plots replicated by treatment type. Three selected plots were treated with loess-balls on the soil surface (high salinity with loess-balls, medium salinity with loess-balls, low salinity with loess-balls) and three were left as an untreated control $(\mathrm{H}=$ high salinity, $\mathrm{M}=$ medium salinity, $\mathrm{L}=$ low salinity). The soil properties were measured including $\mathrm{pH}$, EC and exchangeable cations as well as the growth of Chrysanthemum zawadskiia.

Results: In the results of soil analysis, pH before planting Chrysanthemum zawadskiia was 6.39-6.74 and in September, five months after planting, the acidity was reduced to 5.43-5.89. Electrical conductivity (EC) was measured to be $H>M>$ $L$ with the higher degree of damage by deicing agents. The analysis of deicing exchangeable cations showed that the content of $\mathrm{Ca}^{2+}$ of soils were significantly correlated to deicing exchangeable cations $\left(\mathrm{Ca}^{2+}, \mathrm{Na}^{+}, \mathrm{Mg}^{2+}\right)$ in the shoot part of Chrysanthemum zawadskii. The loess-ball treatment showed a lower content of deicing exchangeable cations than the treatment where Chrysanthemum zawadskiia was planted.

Conclusion: In this study, the use of a new system made of loess-balls is proposed as a soil conditioner to protect soils from the adverse effects of road deicing salts. These data suggest that treatment of soil conditioners and planting Chrysanthemum zawadskiia are effective in mitigation of salt stress on the soils damaged by deicing agents.

Keywords: calcium chloride, loess-ball, phytoremediation, plant salt tolerance, soil salinity

\section{Introduction}

The surface of roads generates a variety of pollutants from a broad range of non-point pollution sources such as wet and dry sediments, vehicle exhausts, vehicle and road abrasion, deicing agents and soil erosion (Mangani et al., 2005). Out of them, deicing agents used to prevent snow or rain from freezing in winter cause the accumulation of

This study was supported by the National Research Foundation of Korea(NRF) grant funded by the Korea government(MSIT) (No. 2018R1A1A3A04079467). Received: August 24, 2020, Revised: October 11, 2020, Accepted: October 13, 2020

First author: Ji Yang, jasmin85@kku.ac.kr, (1) https://orcid.org/0000-0001-5677-2198

*Corresponding author: Jin-Hee Ju, jjhkkc@kku.ac.kr, (1) https://orcid.org/0000-0002-6130-3238 
pollutants on the surface of soil on the roadside (Bauske et al., 1993), and the concentration of chlorides has continued to increase as deicing agents have been continually sprayed every winter (Allert et al., 2012).

Deicing agents can be divided into two types: chloridebased and acetate-based chemical compounds. Chloride-based deicing agents include sodium chloride $(\mathrm{NaCl})$, calcium chloride $\left(\mathrm{CaCl}_{2}\right)$ and magnesium chloride $\left(\mathrm{MgCl}_{2}\right)$, and acetate-based deicing agents include calcium magnesium acetate (CMA), sodium acetate and a mixture of CMA and potassium acetate (CMAK) (Soundararajan et al., 2019). In general, since CMA and CMAK have a low efficiency and a high cost, chloride-based chemical compounds with a lower cost and a higher effectiveness are preferred to them (Yu et al., 2014). Chloride-based deicing agents, however, are easily dissolved, and affect pavements, roadbeds, overpasses, and underground metal pipelines and sewers, having negative effects on trees and flowers, and the environment of the soil on the roadside (Dai et al., 2012). In addition, certain ions contained in chloride-based deicing agents salinize the soil and thus directly affect the physiological stress, nutritional imbalance, the reduction of osmotic potential, etc. (Ju et al., 2019).

As a measure to address environmental problems in urban areas, various ecological engineering approaches have been introduced recently (Hong and Kim, 2016). To manage non-point pollution sources generated after construction, development projects subject to environmental impact assessment are mandated to install facilities that prevent non-point pollution sources in Korea (Ryoo et al., 2012). The 2nd Comprehensive Plan for the Management of Non-point Pollution Sources released in 2012 stated the introduction of low impact development (LID) techniques for various development projects and urban areas and various national projects have been implemented (Hong and Kim, 2016).

The LID techniques are those that maintain the hydrologic mechanisms (infiltration, undercurrent, evapotranspiration) that nature have had before development as much as possible and minimize problems that might occur after development (Choi et al., 2018b). They include bio-retention, rain garden, infiltration trench, bio-swale, porous pavement, green roof, treebox filter, planter box and artificial wetland (Jeon et al., 2018), and the chemical and biological interactions of plants, soil and microorganisms imitate the circulation of natural water and reduce the release of pollutants (Choi et al., 2018a). When designing LID facilities, it is essential to fully review salinity tolerance, pollution resistance, humidity resistance, drought resistance, etc. depending on their location, because the optimal interactions of internal components (plants, soil, etc.) can increase efficiency (Hong and Kim, 2016). It is also important to apply porous vegetation soils to ensure the soils have a sufficient filtration ability and a water retention capacity (Kim and Kim, 2019). The following flowering plants that are applicable to LID facilities and has a high salinity tolerance were studied: Acorus calamus var. angustatus, Aquilegia flabellata var. Pumila, Dianthus chinensis Pratia pedunculata benth, and Tagetes patula (Choi et al., 2018b). There was also a study that selected plants suitable for LID infiltration trenchs including Juncus effusus var. decipiens, Phragmites communis, Equisetum hyemale, Iris sanguinea, Hemerocallis fulva, Iris pseudoacorus, Miscanthus sinensis, Pennisetum alopecuroides, and Liriope platyphylla (Lee et al., 2016).

Chrysanthemum zawadskii, as a wild species of Asteraceae that has a high environmental adaptability and is suitable for the purification of polluted soils (Kwon et al., 2019), has beautiful flowers with a high ornamental value and can pass the winter, and their well-developed roots are very effective in improving the physical conditions of soils and covering soils well (Kim et al., 2020). The soil purification effects of plants are closely related to the growth of plants (Park et al., 2003). Plants with a high salinity tolerance were reported to increase the content of organic matters, and also to reduce the measurement density of soils (Lee et al., 2007). Therefore, Chrysanthemum morifolium with a high salinity tolerance and environmental adaptability was reported to be effective in purifying the soils damaged by deicing agents (Kwon et al., 2019). This study was conducted to verify the effects of planting Chrysanthemum zawadskii and using loess-balls as a soil conditioner on the mitigation of salt stress in areas damaged by deicing agents through an on-site investigation. 


\section{Research Methods}

\section{Site conditions}

This study was conducted at the site where Pinus densiflora f. multicaulis was planted between Konkuk University Sageori and Danwol Samgeori in Chungju, Chungcheongbukdo from April to October, 2019. The roadsides where Pinus densiflora $\mathrm{f}$. multicaulis was planted were created in October, 2000 in the form of street green belt with the total length of $3 \mathrm{Km}$. In 69 green type median barrier blocks, 4 5 Pinus densiflora f. multicaulis trees, a total of 350 trees, were planted in the area. Their average diameter at root collar was $15.76 \pm 3.53 \mathrm{~cm}$, and their average height was $15.53 \pm 1.55 \mathrm{~m}$. The damage caused by deicing agents on the roadside was divided into 3 levels, and was surveyed in March, 2019. Salinity in soils inhibits the growth of plants and it was also reported that the high concentration of $\mathrm{Cl}^{-}$caused the chlorosis of leaves (Hong et al., 2015). Based on the results of the study, Pinus densiflora f. multicaulis trees with their leaf edge discolored were primarily divided into high, medium and low plots. As the secondary classification, soil samples were collected from the Pinus densiflora f. multicaulis blocks at the interval of $50 \mathrm{~m}, 15$ samples for each block, and their acidity $(\mathrm{pH})$ and electrolytic conductivity (EC) were measured. They were divided into 3 plots based on the highest, medium and lowest values and 3 blocks for each plot type were selected based on the results of the primary classification (Table 1). Test beds were installed on the selected blocks.

\section{Plant material and soil conditioner}

Chrysanthemum zawadskii, a species of Asteraceae, that can grow well in a barren environment and has a strong salinity tolerance was selected as a plant material in this

Table 1. Classification of experimental plots by roadside from soil

\begin{tabular}{cccc}
\hline & Yellowing $(\%)$ & $\mathrm{pH}$ & $\mathrm{EC}\left(\mu \cdot \mathrm{cm}^{-1}\right)$ \\
\hline $\mathrm{H}^{\mathrm{z}}$ & $30 \sim 60$ & $6.61 \sim 7.00$ & $0.20 \sim 1.30$ \\
$\mathrm{M}$ & $26 \sim 30$ & $6.42 \sim 6.60$ & $1.10 \sim 0.19$ \\
$\mathrm{~L}$ & $0 \sim 25$ & $5.33 \sim 6.41$ & $0.00 \sim 0.09$ \\
\hline
\end{tabular}

${ }^{\mathrm{z}} \mathrm{H}=$ high salinity soil; $\mathrm{M}=$ medium salinity soil; $\mathrm{L}=$ low salinity soil. experiment (Sun et al., 2002). Chrysanthemum zawadskii trees of which size was relatively uniform (length $=10 \mathrm{~cm}$ ) were purchased from a botanical garden located in Cheonan, Chungnam in April, 2019, and were acclimatized for a week within a greenhouse before using them in this experiment. Loess-balls (Hwangto-Ball, YKbio, Korea) used as a soil conditioner in this study were made by firing loess powder, and large-sized particles (diameter $=5.0 \sim 8.0 \mathrm{~mm}$ ) were used. Since loess-balls have multiple layers and pores, they have a strong physical absorption ability and thus can be utilized in various planting bases (Jeong et al., 2017). In addition, loess-balls were reported to have a strong moisture retention ability, positively affecting the growth of plants ( $\mathrm{Na}$ et al., 2013). Silicon dioxide $\left(\mathrm{SiO}_{2}\right)$ is one of the main components, and it was reported to affect the nutritional physiology of horticultural plants (Ahn et al., 2014). They have been highlighted as an eco-friendly material for their effects such as disinfection, detoxification, filtration and purification (Byun et al., 2009).

\section{Setting of field composed of experiments}

A experiments in this study was created in each of the high, medium and low plots according to the level of damage caused by deicing agents. Experiments were divided into those where the plant materials was planted only ( $\mathrm{H}=$ high salinity, $\mathrm{M}=$ medium salinity, $\mathrm{L}=$ low salinity) and those where the plant material was planted and loess-balls were used to mulching to the height of $1 \sim 2 \mathrm{~cm}$ (H.L = high salinity with loess-ball, M.L = medium salinity with loess-ball, L.L = low salinity with loess-ball) (Fig. 1). Chrysanthemum zawadskii selected as a plant material was planted on empty spaces on flower gardens along the roadside at the interval of $20 \mathrm{~cm}$, and 10 plants of Chrysanthemum zawadskii for each of the 6 experiment divided into those where the plant material was planted only and those where loess-balls were applied together, a total of 180 plants, were planted (Fig. 2).

\section{Sampling and analysis methods}

Soil samples were collected from the control in April before installing experimental plots. In Septemebr, 5 months 


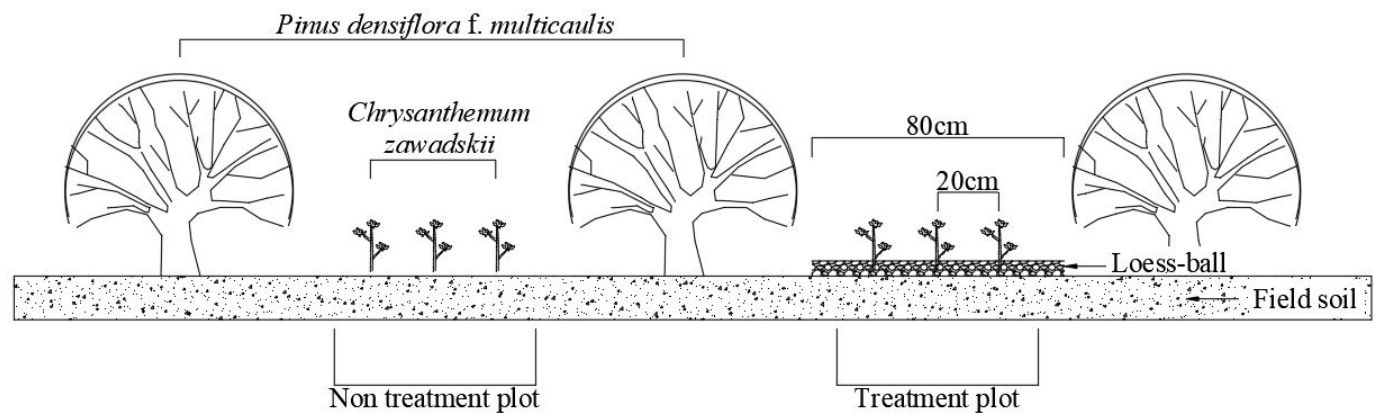

Fig. 1. The schematic diagram for filed experiment.
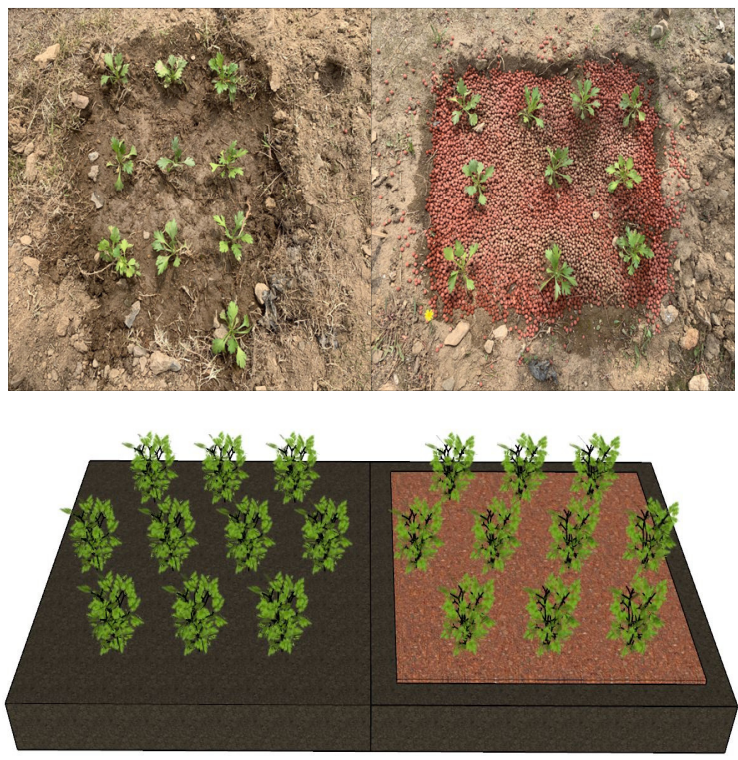

Fig. 2. Field application of the experiment with untreated and 'loess-ball' treatment in deicing agent damaged soil.

after that, the plant material and soil conditioner were removed and samples were collected from the P treatments (planting Chrysanthemum zawadskii) and the P.L treatments (planting Chrysanthemum zawadskii with loess-ball). Samples were collected according to the Soil and Plant Analysis Methodology (Rural Development Adminstration [RDA], 2000) as follows. Five points were selected at the center and north, south, east and west of each of Pinus densiflora f. multicaulis respectively at the interval of 20 $\mathrm{cm}$, and $1 \sim 2 \mathrm{~cm}$ of the topsoil was removed, and $500 \mathrm{~g}$ of the soil at $15 \mathrm{~cm}$ deep, 27 samples for each, was collected. The collected soils were dried at $105{ }^{\circ} \mathrm{C}$ in a dry oven (C-DF, Changshin Sci CO, Korea) for 72 hours and were filtered through a $2 \mathrm{~mm}$ sieve, and the level of $\mathrm{pH}$, EC and deicing exchangeable cations $\left(\mathrm{K}^{+}, \mathrm{Ca}^{2+}, \mathrm{Na}^{+}, \mathrm{Mg}^{2+}\right)$.
For plant analysis, plants were collected and separated into the shoot and root parts. The plant samples were dried with hot air at $70{ }^{\circ} \mathrm{C}$ in a dry oven for 48 hours, and were pulverized for analysis. The samples were diluted with distilled water at the ratio of $1: 5$, and were filtered through a 5B filter (filter paper No. 5B, Adventec, Japan), and the level of $\mathrm{pH}$ and $\mathrm{EC}$ was measured using a $\mathrm{pH}$ meter (ST-3100pH, Ohaus Corp, USA) and a EC meter (ST-3100C, Ohaus Crop, USA). The content of deicing exchangeable cations $\left(\mathrm{K}^{+}, \mathrm{Ca}^{2+}, \mathrm{Na}^{+}, \mathrm{Mg}^{2+}\right)$ within the soils and plants was analyzed by injecting $50 \mathrm{ml}$ of $\mathrm{CH}_{3} \mathrm{COOH}$ and $\mathrm{NH}_{4} \mathrm{OH}$ $(\mathrm{pH} 7.0)$ agents to the samples and filtering them using an inductively coupled plasma atomic emission spectrometer (ICP OES DV-5300, Perkin Elmer, USA).

\section{Statistical analysis}

Statistical analysis was conducted using SPSS Statistics software (version 25, IBM, USA) and Duncan's multiple range test was performed at the significance level of 5\%. The correlation between the chemical properties of soils and plants was analyzed through Pearson's correlation analysis.

\section{Results and Discussion}

Changes in the chemical properties of roadside soils damaged by deicing agents after planting Chrysanthemum zawadskii

\section{Soil acidity (pH)}

$\mathrm{pH}$ as the most important chemical property of soils 
shows a broad range of acidity from 3 to 9 (Shin et al., 2001). Changes in the acidity of soils determine the availability of various nutritive salts that plants can use, and thus are closely related to the growth of plants (Kim et al., 1996). Either extreme acidity or alkalinity is not good for the growth of plants (Shin et al., 2001). The property of soils in April before creating experimental treatments on the study site and 5 months after that were as follows (Table 2).

The $\mathrm{pH}$ level before placing experimental treatments slightly differed depending on the level of damage of deicing agents as follows: H, 6.74; M, 6.69; and L, 6.39. The acidity of soils of the control, P and P.L treatments 5 months after planting Chrysanthemum zawadskii and treating with loess-balls was $6.40,5.81$ and 5.50 respectively. The level of the P treated with Chrysanthemum zawadskii was lower than the control, and that of the P.L treated both with Chrysanthemum zawadskii and loess-balls was lower than the control by 0.6 , showing the lowest $\mathrm{pH}$ level (Table 2). According to the earlier studies on the characteristics of soil leachates depending on the concentration of calcium chloride, the higher the concentration, the higher the acidity of soils as hydrogen ions $\left(\mathrm{H}^{+}\right)$dissolved in soil leachates are combined with water molecules, creating strong acid hydrochloric acid ( $\mathrm{HCl})$ (Ju et al., 2019). Whereas, it was also reported that the $\mathrm{pH}$ level of soils on the roadside after deicing agents were sprayed was slightly higher than the control and that deicing agents alkalized a large amount of saline soils in January, increasing the $\mathrm{pH}$ level over time (Shin et al., 2001). As such, the $\mathrm{pH}$ level in a soil environment and in the form of aqueous solution show the opposite tendency. Carbon dioxide in soils makes plant roots release acid cations like $\mathrm{H}^{+}$, and the increased amount of $\mathrm{H}^{+}$can easily adsorb colloidal particles in soils, which accelerates the release of ions like $\mathrm{Ca}^{2+}$ and $\mathrm{Mg}^{2+}$ (Cheng et al., 2010). Therefore, when chloride deicing agents are accumulated in the soils of the roadside, key components including $\mathrm{Ca}^{2+}, \mathrm{Mg}^{2+}$ and $\mathrm{Na}^{+}$are also accumulated, which seems to increase the level of $\mathrm{pH}$ and EC in the soils (Zhang et al., 2012).

According to the national land use monitoring network of the Ministry of Environment, the average $\mathrm{pH}$ level of

Table 2. The properties of soil chemicals before and after the planting Chrysanthemum zawadskii and loess-ball in field experimental plots

\begin{tabular}{|c|c|c|c|c|c|c|c|}
\hline \multirow{2}{*}{\multicolumn{2}{|c|}{ Treatments $^{\mathrm{x}}$}} & \multirow{2}{*}{$\begin{array}{l}\mathrm{pH}^{\mathrm{y}} \\
(1: 5)\end{array}$} & \multirow{2}{*}{$\begin{array}{c}\text { EC } \\
\left(\mu \mathrm{S} \cdot \mathrm{cm}^{-1}\right)\end{array}$} & \multicolumn{4}{|c|}{ Ex-Cation $\left(\mathrm{Cmol}^{+} \cdot \mathrm{kg}^{-1}\right)$} \\
\hline & & & & $\mathrm{K}^{+}$ & $\mathrm{Ca}^{2+}$ & $\mathrm{Na}^{+}$ & $\mathrm{Mg}^{2+}$ \\
\hline \multicolumn{8}{|c|}{ Before (Apr.) } \\
\hline & & 6.74 & 1.23 & 0.23 & 8.52 & 0.46 & 1.30 \\
\hline & & 6.69 & 1.12 & 0.23 & 7.82 & 0.46 & 1.18 \\
\hline & & 6.39 & 1.04 & 0.22 & 7.62 & 0.39 & 1.06 \\
\hline \multicolumn{8}{|c|}{ After (Sep.) } \\
\hline \multirow{3}{*}{$\mathrm{H}$} & Cont. & $6.41 \mathrm{a}^{\mathrm{z}}$ & $0.85 \mathrm{a}$ & $0.2689 \mathrm{a}$ & $6.6038 \mathrm{a}$ & $0.1270 \mathrm{a}$ & $0.7014 \mathrm{a}$ \\
\hline & $\mathrm{P}$ & $5.81 \mathrm{~b}$ & $0.74 \mathrm{~b}$ & $0.2150 \mathrm{~b}$ & $6.1701 \mathrm{~b}$ & $0.1207 \mathrm{a}$ & $0.6222 \mathrm{~b}$ \\
\hline & P.L & $5.50 \mathrm{c}$ & $0.71 \mathrm{~b}$ & $0.1965 \mathrm{c}$ & $5.5834 \mathrm{c}$ & $0.0862 \mathrm{~b}$ & $0.4774 \mathrm{c}$ \\
\hline \multirow{3}{*}{ M } & Cont. & $6.01 \mathrm{a}$ & $0.84 \mathrm{a}$ & $0.2426 \mathrm{a}$ & $5.8464 \mathrm{a}$ & $0.1244 \mathrm{a}$ & $0.5414 \mathrm{a}$ \\
\hline & $\mathrm{P}$ & $5.76 \mathrm{~b}$ & $0.70 \mathrm{~b}$ & $0.1917 \mathrm{~b}$ & $5.6313 \mathrm{a}$ & $0.0878 \mathrm{~b}$ & $0.5363 \mathrm{a}$ \\
\hline & P.L & $5.29 \mathrm{c}$ & $0.68 \mathrm{~b}$ & $0.1968 \mathrm{~b}$ & $5.4865 \mathrm{a}$ & $0.0788 \mathrm{c}$ & $0.4622 \mathrm{~b}$ \\
\hline \multirow{3}{*}{$\mathrm{L}$} & Cont. & $5.93 \mathrm{a}$ & $0.78 \mathrm{a}$ & $0.2333 \mathrm{a}$ & $5.6175 \mathrm{a}$ & $0.1387 \mathrm{a}$ & $0.3972 \mathrm{a}$ \\
\hline & $\mathrm{P}$ & $5.29 \mathrm{~b}$ & $0.72 \mathrm{~b}$ & $0.2147 \mathrm{~b}$ & $5.5707 \mathrm{a}$ & $0.0709 \mathrm{~b}$ & $0.3764 \mathrm{~b}$ \\
\hline & P.L & $5.14 \mathrm{c}$ & $0.68 \mathrm{~b}$ & $0.1647 \mathrm{c}$ & $3.5724 b$ & $0.0751 \mathrm{~b}$ & $0.3177 \mathrm{c}$ \\
\hline
\end{tabular}

Note. ${ }^{\mathrm{x}} \mathrm{H}=$ high salinity soil; $\mathrm{M}=$ medium salinity soil; $\mathrm{L}=$ low salinity soil; Cont. = non treatments; $\mathrm{P}=$ planting Chrysanthemum zawadskii; P.L = planting Chrysanthemum zawadskii with loess-ball.

${ }_{\mathrm{p}}^{\mathrm{pH}}, \mathrm{EC}$, Ex-Cation represent acidity, electric conductivity, exchangeable cations respectively.

${ }^{\mathrm{z}}$ Means within a column followed by the same letter are not significantly different based on Duncan's multiple range test at $p<.05$. 
soils on the roadside is $6.1 \sim 6.2$, while that of the soils near roads and median strips that are directly affected by deicing agents is 6.4 7.9 (MOE, 1998). The $\mathrm{pH}$ level of the high salinity, medium salinity and low salinity plots surveyed in this study before creating experimental treatments was 6.39 6.74, which was within the range of soils damaged by deicing agents (Table 1). The $\mathrm{pH}$ level of the soils after planting Chrysanthemum zawadskii dropped to 5.25 5.81, which was within the normal range (Shin et al., 2001). In addition, considering that the $\mathrm{pH}$ level suitable for planting landscape trees is 5.0 7.0, and the goal of soil amendment for seedlings and ornamental trees is pH 5.5 6.0 (Nam et al., 2008), the reason why the $\mathrm{pH}$ level decreased over time after planting Chrysanthemum $z a$ wadskii seems to be the cations eluviated by plants from the soils where Chrysanthemum zawadskii was planted, and $\mathrm{Ca}^{2+}, \mathrm{Mg}^{2+}, \mathrm{Na}^{+}$and $\mathrm{K}^{+}$ions leached from the soils during the rainy season in summer (Lee et al., 2006).

\section{Soil electrolytic conductivity (EC)}

Electrolytic conductivity (EC) is an indicator of soil salinity and the EC level of $\mathrm{H}, \mathrm{M}$ and $\mathrm{L}$ plots before creating experimental treatments was $1.23,1.12$ and 1.04 respectively. The level of the control, P and P.L treatments in September, 5 months after planting Chrysanthemum zawadskii, was 0.79 0.85, 0.70 0.74 and 0.68 0.71 $\mu \mathrm{S} \cdot \mathrm{cm}^{-1}$ respectively, showing the highest level in the control treatments and the lowest level in the P.L treatments similar to the results of $\mathrm{pH}$ (Table 2). In general, soils damaged by deicing agents tended to show a high EC level due to a large amount of salts (Nam et al., 2008), and when the EC level is $2.0 \mathrm{dS} \cdot \mathrm{m}^{-1}$ or higher, it is recognized that the soil is under salt stress (Kang et al., 2013). In this study, the EC level before planting Chrysanthemum zawadskii was 1.04 1.23, which was within the range suitable for planting trees $\left(2.0 \mathrm{dS} \cdot \mathrm{m}^{-1}\right)$ (Nam et al., 2008), and the level decreased over time after planting Chrysanthemum zawadskii to $0.68 \sim 0.71 \mu \mathrm{S} \cdot \mathrm{cm}^{-1}$. EC significantly increases in soils where the amount of salts is high (Park et al., 1998), showing a high EC level due to various cations (Zhang et al., 2012). As soils are desalinized, the content of $\mathrm{Mg}^{2+}, \mathrm{Ca}^{2+}$ and $\mathrm{Na}^{+}$tends to decrease as well as the EC level (Kang and Shim, 1998). Chrysanthemum zawadskii, as a well-known species of Asteraceae, is used as a plant material to purify polluted soils (Kwon et al., 2019), as it can metabolize or decompose pollutants within their body, or decompose pollutants through the activity of microorganisms near roots (Park et al., 2004). These characteristics seemed to reduce the content of cations within soils, affecting changes in the EC level.

\section{Content of deicing exchangeable cations $\left(\mathrm{K}^{+}, \mathrm{Ca}^{2+}\right.$, $\left.\mathrm{Na}^{+}, \mathrm{Mg}^{2+}\right)$ in soils}

The content of deicing exchangeable cations in the collected soils was as follows (Table 2). The content of $\mathrm{K}^{+}$ in the control, $\mathrm{P}$ and P.L treatments was 0.23 0.26, $0.19 \sim 0.21$ and $0.16 \sim 0.19 \mathrm{cmol}^{+} \cdot \mathrm{kg}^{-1}$ respectively, showing the highest level in the control and the lowest level in the P.L treated with both Chrysanthemum zawadskii and loess-balls. The content of $\mathrm{Ca}^{2+}$ in the control, $\mathrm{P}$ and P.L treatments was 5.6 6.60, 5.57 6.17 and 3.57 5.58 $\mathrm{cmol}^{+} \cdot \mathrm{kg}^{-1}$ respectively, showing the highest level in the control and the lowest level in the P.L treatments. The content of $\mathrm{Na}^{+}$showed clear differences between the treatments, and the content in the control, P and P.L treatments was $0.12 \sim 0.13,0.07 \sim 0.12$ and $0.07 \sim 0.08 \mathrm{cmol}^{+} \cdot \mathrm{kg}^{-1}$ respectively, showing the highest level in the control and about $1 / 2$ of the level in the P.L treatments. The content of $\mathrm{Mg}^{2+}$ in the control, P and P.L treatments was $0.39 \sim 0.70$, $0.37 \sim 0.62$ and $0.31 \sim 0.47 \mathrm{cmol}^{+} \cdot \mathrm{kg}^{-1}$, also showing the highest level in the control and the lowest level in the P.L treatments. In overall, compared to the control, the treated with Chrysanthemum zawadskii tend to show a low content of deicing exchangeable cations in soils, and the P.L treated with both Chrysanthemum zawadskii and loess-balls showed the even lower content of ions than the $\mathrm{P}$ treatments. In particular, a clear decrease was observed in the content of $\mathrm{Ca}^{2+}, \mathrm{Na}^{+}$and $\mathrm{Mg}^{2+}$, and an excessive accumulation of certain ions $\left(\mathrm{Na}^{+}, \mathrm{Cl}^{-}\right)$in soils affects the photosynthesis and metabolism of plants (Munns and Tester, 2008). The genotypes of salt tolerant plants in general have an ability of controlling $\mathrm{Na}^{+}$and $\mathrm{Cl}^{-}$ions transported to leaves, and some genotypes can tolerate a high concentration of $\mathrm{Na}^{+}$and $\mathrm{Cl}^{-}$in their body (Niu and Cabrera, 
2010). Therefore, the salinity tolerance of Chrysanthemum zawadskii seemed to reduce the concentration of $\mathrm{Ca}^{2+}, \mathrm{Na}^{+}$ and $\mathrm{Mg}^{2+}$ ions.

\section{Effects of soil conditioners on the damage of deicing agents seen from changes in the chemical properties of Chrysanthemum zawadskii}

\section{pH, EC of plants}

The $\mathrm{pH}$ and EC level of Chrysanthemum zawadskii after treating with loess balls are as follows (Fig. 3). The $\mathrm{pH}$ level of the shoot part in the H, H.L, M, M.L, L and L.L treatments was 5.27, 5.16, 5.21, 5.11, 5.11 and 4.96 respectively, showing the highest level in the $\mathrm{H}$ treatments and the lowest level in the L.L treatments. The $\mathrm{pH}$ level of the root part in the H, H.L, M, M.L, L and L.L treatments was 5.39, 5.34, 5.35, 5.32, 5.27 and 5.14 respectively, which was higher by $0.23 \sim 0.31$ than the level of the shoot part. The EC level of the shoot part in the H, H.L, M, M.L, L and L.L treatments was 5.97, 5.08, 5.96, 5.03, 5.48 and 4.92 respectively, showing the highest level in the $\mathrm{H}$ treatments similar to the results of the $\mathrm{pH}$ level. The treated with loess-balls tended to show a lower level than the treated with Chrysanthemum zawadskii only. The EC level of the root part was 3.89, 3.32, 3.56, 3.13, 3.27 and 2.98 respectively, which was clearly lower than that of the shoot part, and that of the L.L treatments was the lowest.

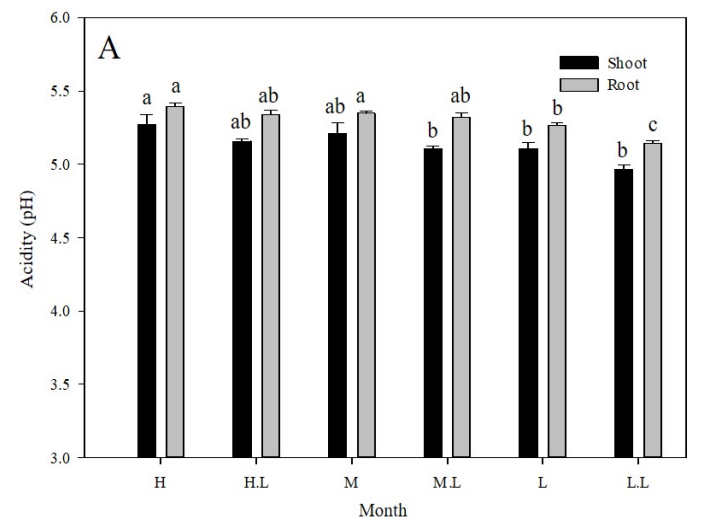

\section{Content of deicing exchangeable cations in the body of plants}

The content of deicing exchangeable cations in Chrysanthemum zawadskii depending on the level of damage caused by deicing agents is as follows (Table 3). The content of $\mathrm{K}^{+}$of the shoot part in the H, H.L, M, M.L, L and L.L treatments was 64.93, 56.01, 56.29, 55.75, 49.89 and $50.65 \mathrm{cmol}^{+} \cdot \mathrm{kg}^{-1}$ respectively, showing the highest content in the H.L treatments and the lowest content in the $\mathrm{L}$ treatments. The content in the $\mathrm{L}$ treatments was slightly lower than the L.L treatments. The content of $\mathrm{Ca}^{2+}$ of the shoot part in the H, H.L, M, M.L, L and L.L treatments were 37.70, 31.02, 31.10, 23.73, 27.91 and 20.59 $\mathrm{cmol}^{+} \cdot \mathrm{kg}^{-1}$ respectively, showing the highest content in the $\mathrm{H}$ treatments and the lowest content in the L.L treatments. The content of $\mathrm{Na}^{+}$in the H, H.L, M, M.L, $\mathrm{L}$ and L.L treatments were $0.50,0.25,0.33,0.19,0.27$ and $0.03 \mathrm{cmol}^{+} \cdot \mathrm{kg}^{-1}$, also showing the highest content in the $\mathrm{H}$ treatments and the lowest content in the L.L treatments. The results of $\mathrm{K}^{+}$and $\mathrm{Ca}^{2+}$ tended to be similar. The content of $\mathrm{Mg}^{2+}$ of the shoot part in the H, H.L, M, M.L, L and L.L treatments was 8.37, 7.58, 8.20, 6.00, 7.15 and 6.27 $\mathrm{cmol}^{+} \cdot \mathrm{kg}^{-1}$ respectively, showing the highest content in the $\mathrm{H}$ treatments and the lowest content in the M.L treatments. The content of $\mathrm{K}^{+}$of the root part in the $\mathrm{H}$, H.L, M, M.L, L and L.L treatments were 57.98, 50.03, $51.94,43.95,44.72$ and $43.58 \mathrm{cmol}^{+} \cdot \mathrm{kg}^{-1}$ respectively. The content of $\mathrm{Ca}^{2+}$ of the root part in the H, H.L, M,

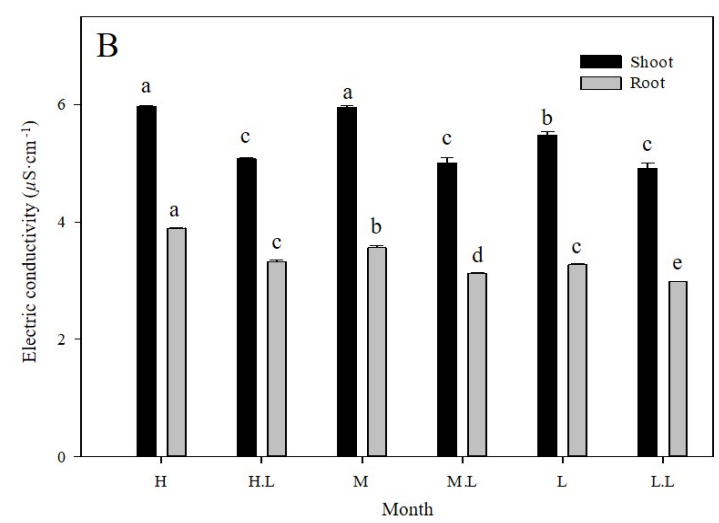

Fig. 3. Acidity $(A)$ and electric conductivity(B) of Chrysanthemum zawadskii as affected by the degree of deicing agent damage $(H=$ high salinity, $H . L=$ high salinity with loess-ball, $M=$ midium salinity, $M . L=$ midium salinity with loess-ball, $\mathrm{L}=$ low salinity, $\mathrm{L} . \mathrm{L}=$ low salinity with loess-ball). Vertical bars means present $\pm \mathrm{SEs}(\mathrm{N}=30)$. Significant differences among the treatments are indicated by the different letters $(p<.05)$. 
M.L, L and L.L treatments were 13.21, 13.16, 12.35, $10.34,11.28$ and $10.43 \mathrm{cmol}^{+} \cdot \mathrm{kg}^{-1}$ respectively, which was similar to the content of $\mathrm{K}^{+}$of the shoot part, but the content in the M.L and L.L treated with loess-balls together was lower than the treated with Chrysanthemum zawadskii only. The content of $\mathrm{Na}^{+}$also showed a similar tendency, as the content in the H, H.L, M, M.L, L and L.L treatments were $3.21,2.84,2.07,1.65,1.17$ and 0.76 $\mathrm{cmol}^{+} \cdot \mathrm{kg}^{-1}$ respectively, showing the highest content in the $\mathrm{H}$ treatments and the lowest content in the L.L treatments. The content of $\mathrm{Mg}^{2+}$ of the root part in the H, H.L, M, M.L, L and L.L treatments was 9.10, 7.68, $7.70,7.39,8.58$ and $6.76 \mathrm{cmol}^{+} \cdot \mathrm{kg}^{-1}$, showing the highest content in the $\mathrm{H}$ treatments and the lowest content in the L.L treatments. Plants have 3 types of tolerance against salinity as follows: tolerance against osmotic stress; selective exclusion of $\mathrm{Na}^{+}$and $\mathrm{Cl}^{-}$ions; and tolerance against accumulated $\mathrm{Na}^{+}$or $\mathrm{Cl}^{-}$ions (Munns and Tester, 2008). It was also reported that the content of exchangeable cations as well as heavy metals including $\mathrm{Cd}$, $\mathrm{Ni}$ and $\mathrm{Zn}$ was reduced in the soils contaminated by heavy metals after planting Chrysanthemum zawadskii and Caryopteris incana, indicating that Chrysanthemum zawadskii has an ability of restoring plants (Park et al., 2003). Therefore, Chrysanthemum zawadskii as a material for plant restoration seemed to contribute to the reduction of the content of deicing exchangeable cations in soils. The results of the content of deicing exchangeable cations in soils were compared, and the content of all the surveyed items including $\mathrm{Ca}^{2+}, \mathrm{Mg}^{2+}, \mathrm{Na}^{+}$and $\mathrm{K}^{+}$in soils was Cont. $>\mathrm{P}>$ P.L, showing the lowest content of deicing exchangeable cations in the P.L treatments. The content of deicing exchangeable cations in the body of plants was $\mathrm{H}>$ H.L $>\mathrm{M}>$ M.L > L > L.L, showing that the higher the level of damage caused by deicing agents, the higher the content of deicing exchangeable cations. The H.L, M.L and L.L treated with loess-balls showed a lower content of deicing exchangeable cations than the treated with Chrysanthemum zawadskii only. This is the ion adsorption effect of loess, and the surface of loess has $(-)$ or $(+)$ charges and draw ions that have the opposite charge (Choi and Lee, 2013). This characteristic of loess-balls increases the absorption of $\mathrm{Na}^{+}, \mathrm{Ca}^{2+}$ and $\mathrm{Mg}^{2+}$ ions within soils, resulting in a lower content of deicing exchangeable cations within the body of Chrysanthemum zawadskii in the treated with loess-balls together than the treated with Chrysanthemum zawadskii only. An earlier study reported that regardless of the type and amount of clay minerals, the treated with clay minerals showed a higher content of the inorganic components $\left(\mathrm{K}^{+}, \mathrm{Ca}^{2+}\right.$ and $\mathrm{Mg}^{2+}$ ) of red pepper than the non treatments (Lee et al., 2012). This result is similar to the results of this study, and loess-balls, a type of clay mineral, has a high moisture retention ability and a high cation exchanging ability, and are expected to contribute to soil improvements as a soil

Table 3. The content of exchangeable cation of Chrysanthemum zawadskii affected by loess-ball treatment and degree of deicing agent damage.

\begin{tabular}{|c|c|c|c|c|c|c|c|c|}
\hline \multirow[b]{2}{*}{ Treatments } & \multicolumn{4}{|c|}{ Shoot } & \multicolumn{4}{|c|}{ Root } \\
\hline & $\begin{array}{c}\mathrm{K}^{+} \\
\left(\mathrm{cmol}^{+} \mathrm{kg}^{-1}\right)\end{array}$ & $\begin{array}{c}\mathrm{Ca}^{2+} \\
\left(\mathrm{cmol}^{+} \mathrm{kg}^{-1}\right)\end{array}$ & $\begin{array}{c}\mathrm{Na}^{+} \\
\left(\mathrm{cmol}^{+} \mathrm{kg}^{-1}\right)\end{array}$ & $\begin{array}{c}\mathrm{Mg}^{2+} \\
\left(\mathrm{cmol}^{+} \mathrm{kg}^{-1}\right)\end{array}$ & $\begin{array}{c}\mathrm{K}^{+} \\
\left(\mathrm{cmol}^{+} \mathrm{kg}^{-1}\right)\end{array}$ & $\begin{array}{c}\mathrm{Ca}^{2+} \\
\left(\mathrm{cmol}^{+} \mathrm{kg}^{-1}\right)\end{array}$ & $\begin{array}{c}\mathrm{Na}^{+} \\
\left(\mathrm{cmol}^{+} \mathrm{kg}^{-1}\right)\end{array}$ & $\begin{array}{c}\mathrm{Mg}^{2+} \\
\left(\mathrm{cmol}^{+} \mathrm{kg}^{-1}\right)\end{array}$ \\
\hline $\mathrm{H}^{\mathrm{y}}$ & $64.93 \mathrm{a}^{\mathrm{z}}$ & $37.70 \mathrm{a}$ & $0.5038 \mathrm{a}$ & $8.3717 \mathrm{a}$ & $57.9847 \mathrm{a}$ & $13.2162 \mathrm{a}$ & $3.2193 \mathrm{a}$ & $9.1043 \mathrm{a}$ \\
\hline H.L & $56.01 \mathrm{bc}$ & $31.02 \mathrm{~b}$ & $0.2593 \mathrm{~d}$ & $7.5857 \mathrm{c}$ & $50.0387 \mathrm{c}$ & $13.1674 \mathrm{a}$ & $2.8428 \mathrm{~b}$ & $7.6806 \mathrm{c}$ \\
\hline M & $56.29 \mathrm{~b}$ & $31.10 \mathrm{~b}$ & $0.3353 b$ & $8.2006 b$ & $51.9445 \mathrm{~b}$ & $12.3511 \mathrm{~b}$ & $2.0753 \mathrm{c}$ & $7.7073 \mathrm{c}$ \\
\hline M.L & $55.75 \mathrm{c}$ & $23.73 \mathrm{~d}$ & $0.1952 \mathrm{e}$ & $6.0017 \mathrm{f}$ & $49.4230 \mathrm{~d}$ & $10.3495 \mathrm{~d}$ & $1.6548 \mathrm{~d}$ & $7.3905 \mathrm{~d}$ \\
\hline $\mathrm{L}$ & 49.89 e & $27.91 \mathrm{c}$ & $0.2779 \mathrm{c}$ & $7.1579 \mathrm{~d}$ & $44.7210 \mathrm{e}$ & $11.2837 \mathrm{c}$ & $1.1728 \mathrm{e}$ & $8.5830 \mathrm{~b}$ \\
\hline L.L & $50.65 \mathrm{~d}$ & $20.59 \mathrm{e}$ & $0.0350 \mathrm{f}$ & $6.2754 \mathrm{e}$ & $43.5899 \mathrm{f}$ & $10.4329 \mathrm{~d}$ & $0.7625 \mathrm{f}$ & $6.7652 \mathrm{e}$ \\
\hline Significant & $* * *$ & $* * *$ & $* * *$ & $* * *$ & $* * *$ & $* * *$ & $* * *$ & $* * *$ \\
\hline
\end{tabular}

Note. ${ }^{\mathrm{y}} \mathrm{H}=$ high salinity; $\mathrm{H} . \mathrm{L}=$ high salinity with loess-ball; $\mathrm{M}=$ midium salinity; M.L = midium salinity with loess-ball; $\mathrm{L}=$ low salinity; L.L $=$ low salinity with loess-ball.

${ }^{Z}$ Means within a column followed by the same letter are not significantly different based on Duncan's multiple range test at $p<0.05$. ${ }^{*} p<.001$ 
conditioner by absorbing the moisture of plants and exchangeable cations.

\section{Effectiveness of planting Chrysanthemum zawadskii and using soil conditioners through correlation analysis}

\section{Correlation analysis between soil chemical properties}

The correlation coefficients between soil chemical properties depending on the treatment of Chrysanthemum zawadskii and loess-balls on the soils of the roadside damaged by deicing agents are as shown in Table 4. The chemical properties of soils depending on the treatment of Chrysanthemum zawadskii and loess-balls had a negative correlation with $\mathrm{pH}\left(-.699^{* *}\right)$, EC $\left(-.396^{* *}\right)$, exchangeable $\mathrm{K}^{+}\left(-.493^{* *}\right)$, exchangeable $\mathrm{Ca}^{2+}\left(-.646^{* *}\right)$, exchangeable $\mathrm{Na}^{+}\left(-.473^{* *}\right)$ and exchangeable $\mathrm{Mg}^{2+}\left(-.872^{* *}\right)$, and the $\mathrm{pH}$ level of soils had a highly positive correlation with EC $\left(.701^{* *}\right)$. In this study, the level of EC before planting Chrysanthemum zawadskii was 1.04 1.23, but gradually decreased to $0.68 \sim 0.71$ in September. The contribution of EC to anions (-) is mostly very high compared to cations (+) (Lee et al., 2010) but in this study the amount of chloride ions $\left(\mathrm{Cl}^{-}\right)$within soils increased by the accumulation of calcium chloride increased the EC level of the soils, but Chrysanthemum zawadskii seemed to dilute soil salts, reducing the EC level. An earlier study reported that deicing agents sprayed in winter increase the acidity of soils on the roadside and also significantly increase the level of EC (Kim et al., 2017). It was also reported that the EC level that can cause salt stress can be maintained at an optimal level by reducing the acidity of soils with organic matters (Choi et al., 2010). Therefore, the $\mathrm{pH}$ and EC level of soils was found to be highly correlated.

The EC level of soils showed the highest correlation with exchangeable $\mathrm{K}^{+}\left(.544^{* *}\right)$ and also showed a positive correlation with exchangeable $\mathrm{Ca}^{2+}\left(.354^{* *}\right)$, exchangeable $\mathrm{Na}^{+}$ $\left(.551^{* *}\right)$ and exchangeable $\mathrm{Mg}^{2+}\left(.391^{* *}\right)$. For this reason, the EC level seemed to slowly decrease during the experiment period and also the content of exchangeable $\mathrm{K}^{+}, \mathrm{Na}^{+}$ and $\mathrm{Mg}^{2+}$ seemed to decrease.

\section{Soil - correlation analysis between the chemical properties of the body of plants}

As loess-balls were used as a soil conditioner in this study, the correlation between the chemical properties of soils and those of Chrysanthemum zawadskii was analyzed (Table 5). The $\mathrm{pH}$ level of soils after treating with loessballs showed the highest correlation with the $\mathrm{pH}$ level of the shoot part of Chrysanthemum zawadskii $\left(.662^{* *}\right)$, and a high correlation coefficient with the EC level of Chrysanthemum zawadskii and all the exchangeable cations, showing a positive correlation. The chemical properties of the root part of Chrysanthemum zawadskii also showed a positive correlation with the $\mathrm{pH}$ level of soils and all the surveyed items similar to the shoot part. The deicing exchangeable $\mathrm{Ca}^{2+}$ of soils showed a high correlation coefficient with the deicing exchangeable $\mathrm{Ca}^{2+}\left(.654^{* *}\right)$ and $\mathrm{Na}^{+}\left(.701^{* *}\right)$ of the shoot part of Chrysanthemum zawadskii, and a positive correlation coefficient with the deicing exchangeable $\mathrm{Mg}^{2+}\left(.607^{* *}\right)$ of the root part. Whereas, the EC level of soils did not show any correlation with the

Table 4. Correlation coefficient between treatment of planting Chrysanthemum zawadskii and chemical properties in roadside soils

\begin{tabular}{|c|c|c|c|c|c|c|c|}
\hline \multirow{2}{*}{ Parameters } & \multicolumn{7}{|c|}{ Soil chemical properties } \\
\hline & Treatment & $\mathrm{pH}$ & $\mathrm{EC}$ & $\mathrm{K}^{+}$ & $\mathrm{Ca}^{2+}$ & $\mathrm{Na}^{+}$ & $\mathrm{Mg}^{2+}$ \\
\hline $\mathrm{pH}$ & $-.669^{* *}$ & 1 & & & & & \\
\hline $\mathrm{EC}$ & $-.396^{* *}$ & $.701^{* *}$ & 1 & & & & \\
\hline $\mathrm{K}^{+}$ & $-.493^{* *}$ & $.606^{* *}$ & $.544^{* *}$ & 1 & & & \\
\hline $\mathrm{Ca}^{2+}$ & $-.646^{* *}$ & $.460^{* *}$ & $.354^{* *}$ & $.694^{* *}$ & 1 & & \\
\hline $\mathrm{Na}^{+}$ & $-.473^{* *}$ & $.690^{* *}$ & $.551^{* *}$ & $.576^{* *}$ & $.541^{* *}$ & 1 & \\
\hline $\mathrm{Mg}^{2+}$ & $-.872^{* *}$ & $.652^{* *}$ & $.391^{* *}$ & $.637^{* *}$ & $.643^{* *}$ & $.425^{* *}$ & 1 \\
\hline
\end{tabular}

${ }^{* *} p<.01$ 
Table 5. Correlation coefficient between the soil and Chrysanthemum zawadskii chloride exchange cations $\left(\mathrm{K}^{+}\right.$, $\mathrm{Ca}^{2+}$, $\mathrm{Na}^{+}, \mathrm{Mg}^{2+}$ ) as effected by treatment of loess-ball and Planting Chrysanthemum zawadskii in roadside soils.

\begin{tabular}{|c|c|c|c|c|c|c|c|c|c|c|c|c|c|}
\hline \multirow{2}{*}{\multicolumn{2}{|c|}{ Parameters }} & \multicolumn{6}{|c|}{ Shoot } & \multicolumn{6}{|c|}{ Root } \\
\hline & & $\mathrm{pH}$ & $\mathrm{EC}$ & $\mathrm{K}^{+}$ & $\mathrm{Ca}^{2+}$ & $\mathrm{Na}^{+}$ & $\mathrm{Mg}^{2+}$ & $\mathrm{pH}$ & $\mathrm{EC}$ & $\mathrm{K}^{+}$ & $\mathrm{Ca}^{2+}$ & $\mathrm{Na}^{+}$ & $\mathrm{Mg}^{2+}$ \\
\hline \multirow{6}{*}{ Soil } & $\mathrm{pH}$ & $.662^{* *}$ & $.730^{* *}$ & $.699^{* *}$ & $.776^{* *}$ & $.750^{* *}$ & $.784^{* *}$ & $.518^{* *}$ & $.816^{* *}$ & $.777^{* *}$ & $.693^{* *}$ & $.711^{* *}$ & $.519^{* *}$ \\
\hline & EC & -.047 & $.418^{* *}$ & $.277^{*}$ & $.427^{* *}$ & $.388^{* *}$ & $.389^{* *}$ & $.347^{*}$ & $.385^{* *}$ & $.270^{*}$ & $.384^{* *}$ & $.339^{*}$ & $.423^{* *}$ \\
\hline & $\mathrm{K}^{+}$ & $.276^{*}$ & $.452^{* *}$ & $.404^{* *}$ & $.640^{* *}$ & $.725^{* *}$ & $.454^{* *}$ & $.460^{* *}$ & $.558^{* *}$ & $.451^{* *}$ & $.431^{* *}$ & $.476^{* *}$ & $.807^{* *}$ \\
\hline & $\mathrm{Ca}^{2+}$ & $.292^{*}$ & $.425^{* *}$ & $.507^{* *}$ & $.654^{* *}$ & $.701^{* *}$ & $.516^{* *}$ & $.524^{* *}$ & $.594^{* *}$ & $.573^{* *}$ & $.518^{* *}$ & $.597^{* *}$ & $.607^{* *}$ \\
\hline & $\mathrm{Na}^{+}$ & $.351^{* *}$ & $.575^{* *}$ & $.928^{* *}$ & $.809^{* *}$ & $.774^{* *}$ & $.685^{* *}$ & $.484^{* *}$ & $.835^{* *}$ & $.894^{* *}$ & $.688^{* *}$ & $.809^{* *}$ & $.594^{* *}$ \\
\hline & $\mathrm{Mg}^{2+}$ & $.567^{* *}$ & $.688^{* *}$ & $.933^{* *}$ & $.873^{* *}$ & $.884^{* *}$ & $.752^{* *}$ & $.710^{* *}$ & $.877^{* *}$ & $.982^{* *}$ & $.733^{* *}$ & $.892^{* *}$ & $.607^{* *}$ \\
\hline
\end{tabular}

soil acidity of the shoot part of Chrysanthemum zawadskii.

\section{Conclusions}

This study was conducted to verify the applicability of Chrysanthemum zawadskii on site and the effectiveness of loess-balls as a soil conditioner for placing low impact development (LID) zones. The acidity of soils before planting Chrysanthemum zawadskii ranged between 6.39 and 6.74 , and the overall $\mathrm{pH}$ level decreased to 5.25 5.81 in September, 5 months after planting. The level of EC in the control was the highest, followed by the planting Chrysanthemum zawadskii and the planting Chrysanthemum zawadskii with loess-ball, showing a significant decrease in the planting Chrysanthemum zawadskii with loess-ball treated with Chrysanthemum zawadskii and loess-balls. The content of deicing exchangeable cations $\left(\mathrm{K}^{+}, \mathrm{Ca}^{2+}\right.$, $\left.\mathrm{Na}^{+}, \mathrm{Mg}^{2+}\right)$ in the soils damaged by deicing agents was the highest in the control, followed by the planting Chrysanthemum zawadskii, and the planting Chrysanthemum zawadskii with loess-ball. The $\mathrm{pH}$ and EC level of Chrysanthemum zawadskii tended to be higher in the treated with loess-balls than the treated with Chrysanthemum zawadskii only, and the content of deicing exchangeable cations showed a close positive correlation with the content of deicing exchangeable cations $\left(\mathrm{K}^{+}, \mathrm{Ca}^{2+}, \mathrm{Na}^{+}, \mathrm{Mg}^{2+}\right)$ of soils and the content of deicing exchangeable cations $\left(\mathrm{K}^{+}\right.$, $\mathrm{Ca}^{2+}, \mathrm{Na}^{+}, \mathrm{Mg}^{2+}$ ) of the shoot and root part of Chrysanthemum zawadskii. In addition, the treated with loess-balls showed a lower absorption rate of deicing exchangeable cations than the control. These results demonstrate that loess-balls are effective in amending soils by assisting the absorption of deicing exchangeable cations in soils and that Chrysanthemum zawadskii is suitable to reduce the EC level of soils damaged by deicing agents and absorb deicing exchangeable cations within soils, using as a plant material in LID vegetation belts. However, it will be necessary to additionally analyze the chemical properties of loess-balls themselves in order to develop loess-balls that are effective and can be applied to broad areas as an eco-friendly soil conditioner for mitigating soil salinity. In addition, the methods of producing loess-balls and the optimal mixing ratio of loess need to be reviewed.

\section{References}

Ahn, B.K., S.G. Han, J.Y. Kim, K.C. Kim, D.Y. Ko, S.S. Jeong, and J.H. Lee. 2014. Influences of silicate fertilizer application on soil properties and red pepper productivity in plastic film house. Korean J. Environ. Agric. 33(4): 254-261. http://dx.doi.org/10.5338/KJEA.2014.33.4.254

Allert, A.L., C.L. Cole-Neal, and J.F. Fairchild. 2012. Toxicity of chloride under winter low-flow conditions in an urban watershed in central Missouri, USA. Bull. Environ. Contam. Toxicol. 89(2): 296-301. https://doi.org/10.1007\%2Fs00 128-012-0673-0

Bauske, B. and D. Goetz. 1993. Effects of deicing-salts on heavy metal mobility zum einfluß von streusalzen auf die beweglichkeit von schwermetallen. Acta Hydrochim. Hydrobiol. 21(1):38-42. https://doi.org/10.1002/aheh.19 930210106 
Byun, M.S., S.H. Lee, and K.W. Kim. 2009. Prolonging vase life of cut flowers using loess and charcoal in holding solution. Korean J. Hortic. Sci. Technol. 27(1):110-115.

Cheng, L., J. Zhu, G. Chen, X. Zheng, N.H. Oh, T.W. Rufty, D.D. Richter and S. Hu. 2010. Atmospheric $\mathrm{CO}_{2}$ enrichment facilitates cation release from soil. Ecol. Lett. 13(3):284-291. https://doi.org/10.1111/j.1461-0248.200 9.01421.x

Choi, H.S., J.S. Hong, F.K.F. Geronimo, and L.H. Kim. 2018a. Implications of $\mathrm{CaCl}_{2}$ application to plants in LID facilities. Water Sci. Technol. 78(5): 1045-1053. https://doi.org/10.2166/wst.2018.364

Choi, H.S., J.S. Hong, S.Y. Lee, and L.H. Kim. 2018 b. Assessment of salt resistance and performances of LID applicable plants. Desalination Water Treat. 18(2):201-207. https://doi.org/10.5004/dwt.2018.21821

Choi, H. J. and S. M. Lee. 2013. Effect of clay on the growth and changes of mineral contents of soybean sprout. J. Korean Geoenviron. Soc. 14(8): 29-35

Choi, M.T., J.I. Lee, Y.U. Yun, J.E. Lee, B.C. Lee, E.S. Yang, and Y.H. Lee. 2010. Relationship between fertilizer application level and soil chemical properties for strawberry cultivationunder greenhouse in Chungnam province. Korean J. Soil. Sci. Fertil. 43(2):153-159.

Dai, H.L., K.L. Zhang, X.L. Xu, and H.Y. Yu. 2012. Evaluation on the effects of deicing chemicals on soil and water environment. Procedia Environ. Sci. 13:2122-2130. https://doi.org/10.1016/j.proenv.2012.01.201

Hong, J.S and L.H. Kim. 2016. Assessment of performances of low impact development (LID) facilities with vegetation. Ecol. Resil. Intrastruct. 3(2):100-109. https://doi.org/10.17820/eri.2016.3.2.100

Hong, S.H., J.S. Kim, J.W. Park, and E.Y. Lee. 2015. A study on the effect of the rhizobacterium, bacillus sp. SH1RP8 and potassium family polymers on the crop growth under saline. Korean Soc. Biotechnol. Bioeng. J. 30(3):97-102. https://doi.org/10.7841/ksbbj.2015.30.3.97

Jeon, J.C, J.H. Jung, Y.S. Kim, and L.H. Kim. 2018. A review of research trend related to NPS and suggestion for research direction in the future. J. Wetl. Res. 20(1):80-93. https://doi.org/10.17663/JWR.2018.20.1.080

Jeong, K.J., C.M. Park, J.S. Kang, K.O. Choi, and J.G. Yoon. 2017. Rooting response of foliage plants affected by rooting stimulator, shading, and root pruning during transplanting to hydroball for hydroculture. Hortic. Sci. Technol. 35 (6):667-679. https://doi.org/10.12972/kjhst. 20170071

Ju, J.H., J. Yang, S.Y. Park, and Y.H. Yoon. 2019. Assessing effects of calcium chloride $\left(\mathrm{CaCl}_{2}\right)$ deicing salt on salt tolerance of Miscanthus sinensis and leachate characterizations. J. Korean Inst. Landsc. Archit. 47(4):61-67. http://dx.doi.org/10.9715/KILA.2019.47.4.061

Kang, B.H and S.I. Shim. 1998. Screening of saline tolerant plants and development of biological monitoring technique for saline stress. 1. Survey of vegetation in saline region and determination of saline tolerance of the plant species of the region. Korean J. Environ. Agric. 17(1):26-33.

Kang, S.S., A.S. Roh, S.C. Choi, Y.S. Kim, H.J. Kim, M.T. Choi, B.G. Ahn, H.K. Kim, S.J. Park, Y.H. Lee, S.H. Yang, J.S. Ryu, Y.G. Sohn, M.S. Kim, M.S. Kong, C.H. Lee, D.B. Lee, and Y.H. Kim. 2013. Status and change in chemical properties of polytunnel soil in korea from 2000 to 2012. Korean J. Soil. Sci. Fertil. 46(6): 641-646. https://doi.org/10.7745/KJSSF.2013.46.6.641

Kim, G.H., S.R. Cho, and H.T. Mun. 1996. Bloom-forming blue-green alga, microcystis flos-aquae, in the lake around reclaimed area of Seosan. Algae 11(2):239-242.

Kim, J.Y., J.Y. Park, Y.H. Yoon, and J.H. Ju. 2017. The seasonal impacts of de-icing salts on soil and vegetation in Chung-ju city. J. Environ. Sci. Int. 26(8):993 998. https://doi.org/10.5322/JESI.2017.26.8.993

Kim, S.J., H.B. Sohn, S.Y. Hong, T.Y. Kim, J.T. Lee, J.H. Nam, D.C. Chang, J.T. Suh, and Y.H. Kim. 2020. Effect of the landscape crop, Chrysanthemum zawadskii on reducing soil loss in highland sloping area. J. Korean Plant Resour. 33(1):15-23. https://doi.org/10.7732/kjpr.2 020.33 .1 .15

Kim, Y.M. and L.H. Kim. 2019. Derivation of sustainability factors of LID facility and strategy of citizen participation for management. J. Wetl. Res. 21(1):57-65. https://doi.org/10.17663/JWR.2019.21.1.057

Kwon, H.J., C.H. Lee, and S.Y. Kim. 2019. Heavy metals uptake capability and growth of fifteen compositae plants for phytoremediation. J. Korean Plant Resour. 32(1):1-8. https://doi.org/10.7732/kjpr.2019.32.1.001

Lee, C.H., S.W. Lee, and H. Lee. 2010. Change of soil chemical properties according to cultivation area and cultural year for Platycodon grandiflorum. Korean J. 
Med. Crop Sci. 18(4):273-279.

Lee, D.G., S.E. Lee, D.H. Kim, H.K. Hong, J.H. Nam, J.S. Choi, M.S. Lee, S.H. Woo, and K.Y. Chung. 2012. Effects of the applications of clay minerals on the early growth of red pepper in growing medium. Korean J. Hortic. Sci. Technol. 30(4):463-470. https://doi.org/10.7 235/hort.2012.12137

Lee, E.Y., K.H. Hyun, and J.S. Jung. 2016. Analysis on appropriate plants of infiltration swale for road runoff. J. Korea Soc. Environ. Restor. Technol. 19(5):19 2. http://dx.doi.org/10.13087/kosert.2016.19.5.19

Lee, J.G., B.D. Lee, and H.J. Kang. 2006. Characteristics of deicing agent concentrations in highway roadside soils. Proceedings of 2006 Regular Conference of the Korean Society of Civil Engineers (pp. 1742-1745). Gwangju: Korean Society of Civil Engineers.

Lee, K.B., J.G. Kang, J. Li, D.B. Lee, C.W. Park, and J.D. Kim. 2007. Evaluation of salt-tolerance plant for improving saline soil of reclaimed land. Korean J. Soil. Sci. Fertil. 40(3):173-180.

Mangani, G., A. Berloni, F. Bellucci, F. Tatàno, and M. Maione. 2005. Evaluation of the pollutant content in road runoff first flush waters. Water Air Soil Pollut. 160(1-4): 213-228. https://doi.org/10.1007/s11270-005-2887-9

Ministry of Environment. 1998. Standard methods for soil analysis. Sejong, Korea: Ministry of Environment.

Munns, R. and M.Tester. 2008. Mechanisms of salinity tolerance. Annu. Rev. Plant Biol. 59:651-681. https://doi.org/10.11 46/annurev.arplant.59.032607.092911

Na, T.S., K.J. Choi, B.G. Yoon, M.S. Cho, H.G. Kim, H.J. Kim, D.M. Son, and Y.K. Yoo. 2013. Effect of mixture media of red clay and peatmoss on quality and drainage solution in hydroponics of Solanum lycopersicum 'Mascar a'. Protected Hortic. Plant Fact. 22(1): 1-6. https://doi.or g/10.12791/KSBEC.2013.22.1.001

Nam, W., Y.S. Kwak, I.H. Jeong, D.B. Lee, and S.S. Lee. 2008. Plant distributions and physicochemical characteristics of topsoil on the reclaimed dredging area. J. Korean Inst. Landsc. Archit. 36(3):52-62.

Niu, G. and R.I. Cabrera. 2010. Growth and physiological responses of landscape plants to salinity water irrigation: A review. HortScience 45(11): 1605-1609. https://doi.org/10.21273/HORTSCI.45.11.1605
Park, C.B., K.Y. Choi, and Y.B. Lee. 1998. Effect of $\mathrm{NaCl}$ on growth, mineral nutrient uptake and stress response of coarse and medium texture zoysiagrasses (Zoysia japonica Steud). Proceedings of Korea Society for Turfgrass Science Regular General Meeting and Academic Presentation Vol. 11 (pp.1-13). Daejeon, Korea: Korea Society for Turfgrass Science.

Park, E.A. Y. Choi, S.G. Lee, and M.H. Chiang. 2003. Effect of soil conditioners for contaminated soil of abandoned zinc mine area on growth of Chrysanthemum zawadskii and Caryopteris incana(Tunb) miq. J. Bio-Environ. Control 12(4):245-251.

Park, J.B., J.H. Yoo, and C.M. Kwak. 2004. Phytoremediation. J. Korean Geoenviron. Soc. 20(3): 42-50

Rural Development Adminstration. 2000. Methods of soil and plant analysis. Suwon, Korea: Author.

Ryoo, Y.K., C.G. Kim., S.B. Hong, and K.S. Kim. 2012. A study on the reduction countermeasure for calcium chloride of non-point pollution source. Proceedings of 2012 Conference of the Korean Geo-environmental Society (pp.55-59). Seoul: Korean Geo-environmental Society.

Shin, J.H., H.R. Heo, J.S. Shin, M.Y. Kim, and J.Y. Shin. 2001. A study of effects on environment from road deicings. Korean J. Sanit. 16(4):31-37.

Soundararajan, P., A. Manivannan, C.H. Ko, J.E. Park, and B.R. Jeong. 2019. Evaluation of relative toxicity caused by deicing agents on photosynthesis, redox homeostasis, and the osmoregulatory system in creeper-type plants. Hortic. Environ. Biotechnol. 60(2):175-186. https://doi.org/ 10.1007/s13580-018-0117-9

Sun, B. Y., M.R. Sul, J.A. Im, C.H. Kim, and T.J. Kim. 2002. Evolution of endemic vascular plants of Ulleungdo and Dokdo in Korea - floristic and cytotaxonomic characteristics of vascular flora of Dokdo - Korean J. Plant Taxon. 32(2):143-158.

Yu, W.B., X. Yi, M. Guo, and L. Chen. 2014. State of the art and practice of pavement anti-icing and de-icing techniques. Sci. Cold Arid Reg. 6(1): 14-21. https://doi.org/10.3724/SP.J.1226.2014.00014.

Zhang, Y., F. Y. Li, T. T. Sun, and J. L. Wang. 2012. Effect of deicing salts on urban soils and the health of roadside pines (Pinus tabulaeformis) in Northeast Chin a. Appl. Mech. Mater. 178:353-356. https://doi.org/10.4 028/www.scientific.net/AMM.178-181.353 